\section{Evidence-based mental health care}

Evidence-Based Mental Health Care. Simon Hatcher, Rob Butler and Mark Oakley-Browne. Pp. 161. Edinburgh: Elsevier Churchill Livingstone. 2005. ISBN 0044307066.

'... the fact that an opinion has been widely held is no evidence whatever that it is not utterly absurd; indeed in view of the silliness of the majority of mankind, a widespread belief is more likely to be foolish than sensible...'

Bertrand Russell: Marriage and Morals (1929)

Evidence-based practice has become one of the latest buzzwords of the 21 st-century medical fraternity. Non-evidencebased practices, like lobotomies, prolonged sleep therapy, insulin coma therapy, malaria fever therapy and depatterning (or 'brainwashing'), and concepts like 'the schizophrenogenic mother' as a cause for schizophrenia, remind us of its importance. We are told only to believe something if it has been proven beyond all doubt and the research has been properly scrutinised.

Everyone is expected to be competent in doing this, but very few of us were trained in how to 'critically appraise' research, and many feel overwhelmed by this. Most books written on this topic are full of complicated concepts and complex statistics, do not bring theory and practice together, or have focused on internal medicine. All mental health clinicians want the best possible evidence-based care for their patients, but many are unsure how to find the appropriate evidence to help a specific patient or how to appraise it. If this is how you feel, then this is the book for you.

This book is a very easy step-by-step guide on how to practise evidence-based mental health care. It masterfully covers both theoretical concepts and practice. It is written in a straightforward and easy to understand manner and uses lots of practical examples and exercises (with answers included) to ensure that you truly master your newly acquired skills. The text is supplemented by flow-diagrams, graphs and pictures to illustrate or summarise concepts. Sticky topics, like what to do when there is no evidence, are also covered.

This book is a really excellent resource for all mental health workers. Psychiatrists and trainee psychiatrists will find it a very useful text that is likely to change their clinical practice. Its use is not restricted to doctors, however. Anyone who does clinical work with mental health patients will benefit from working through this book, including psychologists, psychiatric nurses, occupational therapists, social workers and other workers in this field. I can strongly recommend it to anyone who wishes to improve their skills in evidence-based medicine.

\section{Lize Weich}

